\title{
AN APPLICATION METHODOLOGY BASED ON AHP AND SIMULATION TO STUDY INVENTORY MANAGEMENT PROBLEMS
}

\author{
Francesco Longo* \\ University of Calabria \\ Faculty of Engineering \\ Arcavacata di Rende, CS, ITALY \\ f.longo@unical.it \\ Fabio De Felice \\ University of Cassino \\ Faculty of Engineering \\ Cassino, FR, ITALY \\ E-mail: defelice@unicas.it \\ Antonella Petrillo \\ University of Cassino \\ Faculty of Engineering \\ Cassino, FR, ITALY \\ E-mail: a.petrillo@unicas.it \\ Armando Carlomusto \\ University of Cassino \\ Faculty of Engineering \\ Cassino, FR, ITALY \\ E-mail: a.carlomusto@unicas.it
}

\begin{abstract}
The purpose of this paper is to propose a new application methodology to evaluate the best inventory strategy through the use of an integrated approach based on Analytic Hierarchy Process (AHP) and Simulation. The application methodology, which is loosely based on Simulation approach, incorporates the AHP approach to delineate and rank the relative importance weight of expressed judgments to analyze global supply chain decisions. Definitely we apply the AHP analysis in order to reach better decisions for the simulation results. The approach has been validated in a real case study concerning the three-echelon supply chain operating in the beverage sector.
\end{abstract}

Keywords: AHP, Modeling \& Simulation, Supply Chain, Inventory Control Policies.

\section{Introduction}

Inventory decisions are high risk and high impact for supply chain management. Without a proper inventory management, lost sales and customer dissatisfaction may occur. Likewise, inventory planning is critical to manufacturing. Material or component shortages can shut down a manufacturing line or force modification of production schedules, which creates additional cost and potential finished goods shortages. Just as out of stock occurrences can disrupt planned marketing and manufacturing operations, inventory overstocks also create operating problems and additional costs.

Management of inventory resources requires an understanding of the principles, cost, impact, and dynamics. When formulating inventory management policy, specific inventory relationships must be considered. The main key indicators of inventory performance are costs, service level and average on hand inventory (Bowersox et al,

\footnotetext{
* Corresponding author
} 
2002). In this context a modern supply chain design needs to deal with the trade-offs between a variety of factors, including for example location and associated (fixed) operating costs of distribution centers (DCs), total transportation costs, and storage holding.

To improve supply chain inventory management we decided to propose a new application methodology based on the combined use of Analytic Hierarchy Process (AHP) and Modeling \& Simulation. In particular we propose a detailed study of a three-echelon inventory system and we compare the actual inventory system with optimistic and pessimistic scenarios. We, also describe the benefits of the use an integrated approach and the added advantages of using AHP in order to maximize shareholder value.

The paper is organized as follows: section 2 surveys the existing literature about AHP and Simulation applied to supply chain inventory systems. Section 3 describes the proposed methodology together with an application example based on a real case study. Finally in the last section 4, conclusions and research guidelines for future work are summarized.

\section{Literature overview: AHP and Simulation}

The variety of research in the management of inventory and demand forecasting is very broad in scope over the past decades. We briefly review the researches which are most relevant for our work. In particular we analyzed publications regarding Analytic Hierarchy Process (AHP) apply to inventory management problems and publications regarding inventory management based on Modelling \& Simulation approach.

AHP is a multiple criteria decision-making tool developed by prof. T.L. Saaty that has been used in almost all the applications related with decision-making (Omkarprasad S. Vaidya et al., 2006). The specialty of AHP is its flexibility to be integrated with different techniques like Linear Programming, Quality Function Deployment, Fuzzy Logic, etc (De Felice and Petrillo, 2010).

We note that AHP is one of the most regarded techniques to inventory management and it was proposed independently by many authors. Among them S.G. Li, X. Kuo developed an enhanced fuzzy neural network (EFNN) based on AHP for managing automobile spares inventory in a central warehouse. Inventory Management typically involve the selection of the most appropriate project delivery method as key project success factor that can be addressed using AHP (Al Khalil, 2002; Byun, 2001; Jukka Korpela et al 2007) or it involve vendor selection (Tam and Tummala, 2001). To identify an optimal order allocation strategy (Prem Prakash Gajpal et al. 1994), or a proper classification system (Ozan Cakir et al., 2008) AHP method has been utilized by several authors. Many research works identify, as critical parameters in defining the optimal inventory control policies, the customers' demand pattern, the lead times and the information sharing. Most of the cases propose a comparative analysis of different operative scenarios or configurations (Modelling \& Simulation is often used as what-if analysis or cognitive tool). The influence on supply chain performance of the most applied inventory policies (economic order quantity with stationary demand and dynamic economic lot size with non-stationary demand) is reported in Zipkin (2000). Bertsimas and Thiele (2006) propose an approach that takes into consideration demand uncertainty and provides as results insights about the optimal policy (considering an optimal tradeoff between performance and protection against uncertainty). Other works related to inventory systems are reported in Zhao et al. (2004) that presented a modified economic ordering quantity for a single supplier- retailer system in which production, inventory and transportation costs are all considered. Conjoint studies for the network planning are presented by Wasner and Zapfel (2004) although they are interested on solving the location problem together with the routing problem. The state-of-the-art overview highlights that the AHP has never been used in combination with Simulation to investigate inventory management problems along the supply chain. Thus, in such a context, our research differs from previous work mainly because we consider an integrated approach based on multi criteria methodology and simulation approach.

\section{The application methodology}

In this paragraph an application methodology based on AHP and simulation is presented. AHP breaks down a complex, unstructured situation into basic elements. The process arranges these elements in a hierarchy of nodes with branches and translates subjective judgments on the relative importance of each element into numerical values based on a pairwise comparison/judgment scale. Finally, AHP 
synthesizes these judgments to provide a quantitative measure of value. A judgment or comparison is the numerical representation of a relationship between two elements that share a common parent. To express judgment we use the 1-9 scale shown in Table 1 for the element on the left over the element at the top of the matrix (Saaty, 2001). Judgments in a matrix may not be consistent. In mathematical terms, the verification of consistency is expressed through the calculation main eigenvalue $\lambda$ max: if the value is $n$ then the matrix (of rank $n$ ) is consistent. More $\lambda$ max is equal to the number $n$ more consistent is the result. The deviation of the coherence is shown with the index of consistency (I.C.):

I.C. $=\left(\lambda_{\max }-n\right) /(n-1)<0.10$

where $\mathrm{n}$ is the number of components evaluated in the pairwise comparison matrix, and $\lambda$ max is the largest eigenvalue characterizing the previous matrix. Inconsistency may be considered a tolerable error in measurement only when it is of a lower order of magnitude (10 percent) than the actual measurement itself; otherwise the inconsistency would bias the result by a sizable error comparable to or exceeding the actual measurement itself (Saaty, 2005).

In Figure 1 the steps of the application methodology are illustrated.

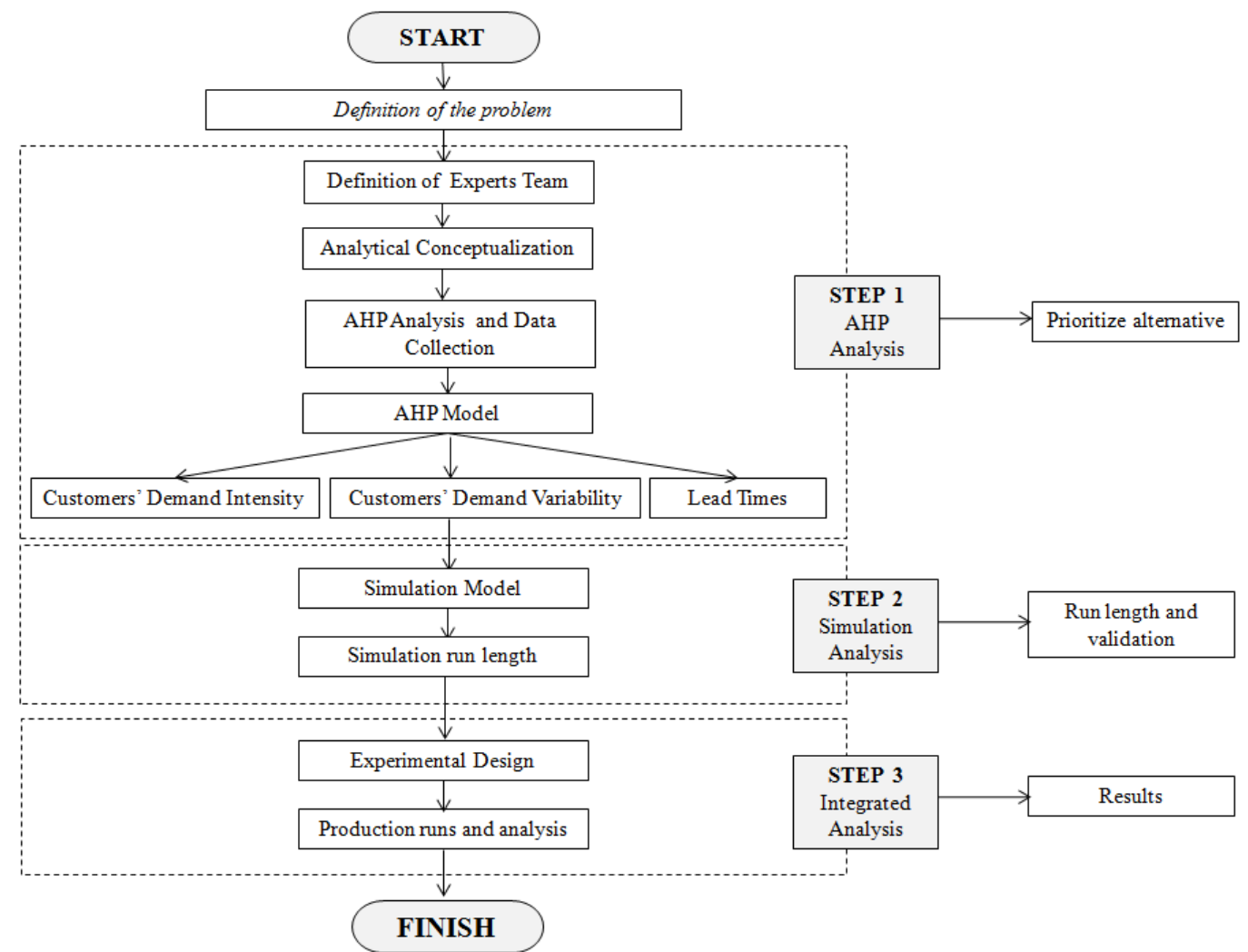

Figure 1. Steps of proposed application methodology

\subsection{Step 1: AHP Analysis}

According to the principles of AHP, the first step in the analysis is to identify the criteria on which the analysis of the alternative is based. The criteria are then structured into a hierarchical form to represent the relationships between the identified factors. The main step in using the AHP is to derive priorities for each element in the hierarchy. The priorities are set by comparing each set of elements with respect to each of the elements in a higher level. In a typical AHP-hierarchy, the alternatives to be analysed would be added to the lowest level of 
the hierarchy. The alternatives would then be analysed in a pairwise manner with regard to each subcriterion in order to derive the overall priorities for the decision alternatives.

\section{Definition of Experts Team}

In order to work correctly to determine criteria and alternatives, an inter functional team was set up. It was composed of 2 delegates from the 5 main departments of the firm (commercial, technical, production, logistics and purchase departments). The solutions are designed in groups by using morphological analysis and the brainstorming technique. This team gave a description of the needs that a customer expects to satisfy. This procedure was repeated for the different groups. After sharing the list, the groups were set up again, and together defined a pooled ranking.

\section{Analytical Conceptualization}

For our case study we analyzed a three-echelon supply chain operating in the beverage sector. The supply chain consists of 5 manufacturing plants, 2 distribution centers (herein after DCs), 20 big retailers and more than 100 items. Each manufacturing plant produces a certain mix of products activating different production processes. Plants are 'make to order' systems and they don't have warehouses, thus items are sent to DCs just after the production. The transportation activities are carried out by a third-party logistics (3PL) according to low variable lead times. In our conceptual model we assume constant transportation lead times. We use an estimate of the lead time standard deviation only for safety stock calculations. The DCs use a continuous review policy, $(r, R)$, with fixed review period. Consider the distribution centre $\mathrm{i}$ and the item $\mathrm{j}$; the $(\mathrm{r}, \mathrm{R})$ policy places an order every time the inventory position falls below the reorder point $\mathrm{ri}, \mathrm{j}(\mathrm{t})$. The ordered quantity will bring the inventory position to the target level Ri,j(t). The inventory position, IPi,j(t), is the on-hand inventory, plus the quantity already on order, minus the quantity to be shipped. The reorder point ri,j(t) is the lead time demand (evaluated as the daily demand, Di,j(t), averaged over the last T periods, times the lead time, LTi,j(t)) plus the safety stock, $\mathrm{SSi}, \mathrm{j}(\mathrm{t})$, as expressed in equation (2):

$$
n i, j(t)=L T i, j(t) \frac{\sum_{i}^{E+T-1} D i, j(t)}{T}+55 i, j(t)
$$

Let $\mathrm{Tp}$ be the review period, the target level $\mathrm{Ri}, \mathrm{j}(\mathrm{t})$ is the sum of the average demand over the review period and reorder point ri,j(t), as expressed in equation (3):

$R i, j(t)=L T i, j(t) \frac{\sum_{i}^{i+T-1} D i, j(t)}{T_{p}}+n i, j(t)$

The order emission condition and the quantity to be ordered, Qi,j(t), respectively, follow equations (4) and (5):

$$
\begin{aligned}
& I P i_{i} j(t)<r_{i} j(t) \\
& Q i, j(t)=R i_{j} j(t)-I P i_{i} j(t)
\end{aligned}
$$

We would like to note that even though the distribution centres use the same inventory control policy, they do not use the same demand forecasting methodology. The first distribution centre uses the moving average methodology; the second and one use the single exponential smoothing. Every day the DCs try to satisfy retailers' demand. Unsatisfied demand is recorded for performance indexes calculation. Item distribution is made, giving each retailer the same priority. In case of reduced stock the available quantity is proportionally subdivided among the retailers. Transportations between DCs and retailers are assured by a 3PL, guarantying low variable lead times. As in the case of plants we assume, in our conceptual model, constant lead times and we use an estimate of the lead time standard deviation for safety stock calculations.

The retailers follow a similar operative procedure in terms of customers and inventory management. The inventory control policy adopted by each retailer is based on continuous review. 
In order to test a comprehensive set of inventory policies, the simulation model is implemented considering for each supply chain node (both retailers and DCs) its own policy plus the three remaining policies. Herein after, let us identify the actual retailers' policy with ICP1, the integration of such a policy with dynamic safety stock, ICP2, the actual DCs' policy with ICP3 and the policy based on optimal review period with ICP4.

\section{AHP Analysis and Data Collection}

As we said the case study proposed regards a supply chain operating in the beverage sector. The firm management has highlighted three main value added policies: (1) Customers' Demand Intensity; (2) Customers' Demand Variability; and (3) Lead Times. Thus, these general strategies have been decomposed in criteria cluster and following a description list of the most important variables and information collected for each plant, distribution centre and retailer, is proposed (see Table 1).

Table 1. Criteria and Sub Criteria description

\begin{tabular}{|l|l|}
\hline \multicolumn{1}{|c|}{ CLUSTER } & \multicolumn{1}{|c|}{ SUB CRITERIA } \\
\hline Cluster Plants & (S1) Process Time \\
& (S2) Setup Time \\
& (S3) Lead Time \\
& (S4) Number and type of machines \\
& (S5) Bill of materials \\
& (S6) Items mixture \\
\hline Cluster Distribution Centres & (S7) Lead Time \\
& (S8) Inventory control policy \\
& (S9) Forecast method \\
& (S10) Inventory Costs \\
& (S11) Items mixture \\
\hline Cluster Retailers & (S12) Demand arrival process \\
& (S13) Customer demand \\
& (S14) Lead Time \\
& (S15) Inventory control policy \\
& (S16) Forecast method \\
& (S17) Inventory Costs \\
& (S18) Items mixture \\
\hline
\end{tabular}

Main indicators that characterize the plants (see Table 2), the distribution centres (see Table 3) and the retailers (see Table 4) have been evaluated for both models development.

Table 2. Indicator characterizing the 5 plants

\begin{tabular}{|l|c|c|c|c|c|}
\hline \multicolumn{5}{|c|}{ Cluster Plants } \\
\hline & $P 1$ & $P 2$ & $P 3$ & $P 4$ & L5 \\
\hline S1 & high & Low & Low & average & high \\
\hline S2 & $\begin{array}{c}\text { over } 5 \\
\text { times at day }\end{array}$ & $\begin{array}{c}2-3 \\
\text { times at day }\end{array}$ & times at day & $\begin{array}{c}\text { over } \\
\text { times at day }\end{array}$ & $\begin{array}{c}\text { times at day } \\
\text { times }\end{array}$ \\
\hline S3 & once a week & once a week & 2 times a week & once in 2 weeks & once a week \\
\hline S4 & average & High & Average & high & average \\
\hline S5 & less than 50 & between 50-70 & between 50-70 & more than 80 & between 50-70 \\
\hline S6 & low & High & Low & average & average \\
\hline
\end{tabular}

Table 3. Indicator characterizing the 2 distribution centres

\begin{tabular}{|l|c|c|}
\hline \multicolumn{3}{|c|}{ Cluster Distribution Centres } \\
\hline & D1 & D2 \\
\hline S7 & 2 times a week & 2 times a week \\
\hline
\end{tabular}




\begin{tabular}{|l|c|c|}
\hline S8 & excellent & good \\
\hline S9 & Good & low \\
\hline S10 & Medium & low \\
\hline S11 & High & average \\
\hline
\end{tabular}

Table 4. Indicator characterizing the 10 retailers

\begin{tabular}{|c|c|c|c|c|c|c|c|c|c|c|}
\hline \multicolumn{11}{|c|}{ Cluster Retailers } \\
\hline & $R 1$ & $R 2$ & $R 3$ & $R 4$ & $R 5$ & R6 & $R 7$ & $R 8$ & R9 & $R 10$ \\
\hline$S 12$ & $6 \mathrm{~h}$ & $4 \mathrm{~h}$ & $4 \mathrm{~h}$ & $8 \mathrm{~h}$ & $8 \mathrm{~h}$ & $4 \mathrm{~h}$ & $8 \mathrm{~h}$ & $6 \mathrm{~h}$ & $6 \mathrm{~h}$ & $4 \mathrm{~h}$ \\
\hline$S 13$ & average & unsatisfactory & average & $\begin{array}{c}\text { below } \\
\text { average }\end{array}$ & unsatisfactory & $\begin{array}{c}\text { below } \\
\text { average }\end{array}$ & $\begin{array}{l}\text { below } \\
\text { average }\end{array}$ & average & average & average \\
\hline$S 14$ & $\begin{array}{l}2 \text { times } \\
\text { a week }\end{array}$ & $\begin{array}{c}\text { once in } 2 \\
\text { weeks }\end{array}$ & $\begin{array}{c}\text { once a } \\
\text { week }\end{array}$ & $\begin{array}{l}\text { once a } \\
\text { week }\end{array}$ & $\begin{array}{c}\text { once in } 2 \\
\text { weeks }\end{array}$ & $\begin{array}{l}2 \text { times } \\
\text { a week }\end{array}$ & $\begin{array}{c}\text { once in } \\
2 \\
\text { weeks }\end{array}$ & $\begin{array}{l}\text { once a } \\
\text { week }\end{array}$ & $\begin{array}{l}\text { once in } \\
2 \text { weeks }\end{array}$ & $\begin{array}{l}\text { once a } \\
\text { week }\end{array}$ \\
\hline$S 15$ & excellent & good & good & low & excellent & Good & low & excellent & low & low \\
\hline$S 16$ & good & good & excellent & good & good & Good & good & low & excellent & good \\
\hline S17 & high & medium & low & high & medium & Low & low & high & medium & low \\
\hline 518 & high & average & low & low & high & Average & average & average & low & high \\
\hline
\end{tabular}

\section{AHP Model}

Here below in Figure 2 is the AHP Model proposed.

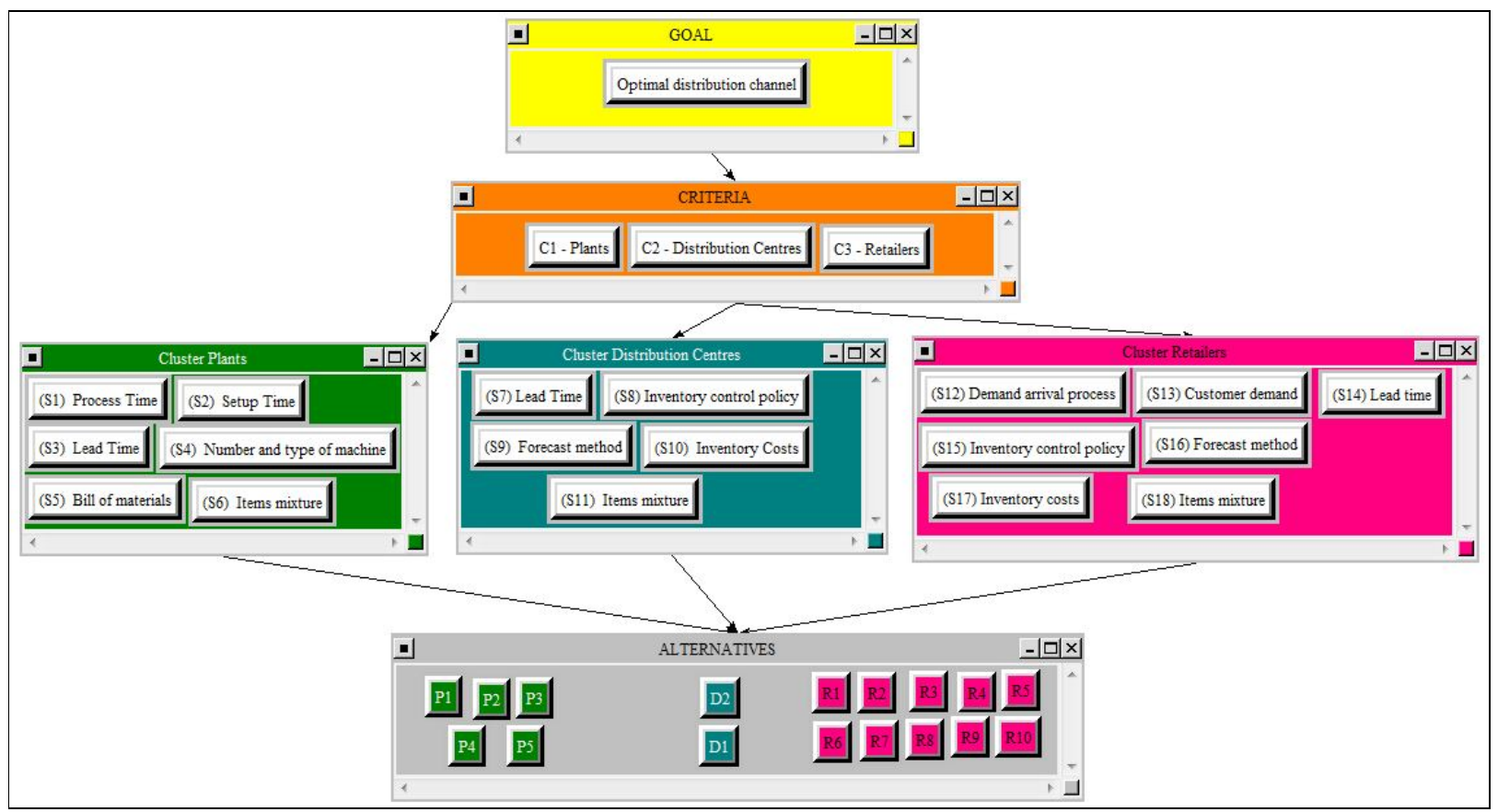

Figure 2. The AHP Model

In Table 5 AHP results are shown for global priorities regarding different alternatives.

Table 5. Results for global priorities regarding different alternatives

\begin{tabular}{|l|c|l|c|}
\hline Alternatives & Priorities & Alternatives & Priorities \\
\hline D1 & 1.00 & R3 & 0.106 \\
\hline D2 & 0.818 & R4 & 0.091 \\
\hline P1 & 0.810 & R5 & 0.089 \\
\hline
\end{tabular}




\begin{tabular}{|l|l|l|l|}
\hline P2 & 0.697 & R6 & 0.122 \\
\hline P3 & 0.609 & R7 & 0.091 \\
\hline P4 & 0.641 & R8 & 0.091 \\
\hline P5 & 0.544 & R9 & 0.122 \\
\hline R1 & 0.098 & R10 & 0.091 \\
\hline R2 & 0.093 & & \\
\hline
\end{tabular}

In Tables 6 are shown AHP results for global priorities regarding different criteria.

Table 6. Results for global priorities regarding different criteria

\begin{tabular}{|l|l|}
\hline Criteria & Priorities \\
\hline C1 - Plants & 0.179 \\
\hline C2 - Distribution Centres & 0.098 \\
\hline C3 - Retailers & 0.054 \\
\hline
\end{tabular}

In Tables7 are shown AHP results for global priorities regarding different clusters

Table 7. Results for global priorities regarding different clusters

\begin{tabular}{|l|l|}
\hline Clusters & Priorities \\
\hline (S1) Process Time & 0.029 \\
\hline (S2) Setup Time & 0.027 \\
\hline (S3) Lead Time & 0.030 \\
\hline $\begin{array}{l}\text { (S4) Number and type of } \\
\text { machine }\end{array}$ & 0.028 \\
\hline (S5) Bill of materials & 0.026 \\
\hline (S6) Items mixture & 0.029 \\
\hline (S7) Lead Time & 0.019 \\
\hline (S8) Inventory control policy & 0.018 \\
\hline (S9) Forecast method & 0.020 \\
\hline (S10) Inventory Costs & 0.016 \\
\hline (S11) Items mixture & 0.017 \\
\hline (S12) Demand arrival process & 0.007 \\
\hline (S13) Customer demand & 0.009 \\
\hline (S14) Lead time & 0.008 \\
\hline (S15) Inventory control policy & 0.007 \\
\hline (S16) Forecast method & 0.006 \\
\hline (S17) Inventory costs & 0.007 \\
\hline (S18) Items mixture & 0.008 \\
\hline
\end{tabular}

\subsection{Step 2: Simulation Analysis}

The simulator recreates the logical connections, the flow of items and information among the various nodes of the supply chain. Two different performance measures are used to investigate the inventory management problem in each supply chain node and in correspondence of each scenario: the fill rate and the on-hand inventory. The fill rate is the ratio between the number of satisfied orders and the total number of received orders (for each supply chain node). The on-hand inventory is the average value between the on-hand inventory before the business hour and the on-hand inventory after the business hour.

The accuracy and the quality throughout a simulation study are assessed by conducting verification and validation processes (Balci 1998). The simulator verification has been made using a dynamic technique (debugging). All the simple++ code written within the simulation model has been debugged, correcting errors 
and carrying out, as consequence, the simulation model verification. The simulation run length (in order to obtain significant simulation results) has been evaluated by using the mean square pure error analysis (MSPE) for each supply chain node. According to the MSPE theory when multiple performance measures are used then the simulation run length is the longest value evaluated by the mean square pure error analysis (450 days). Finally the validation of the simulation model has been carried out by using the Face Validation technique.

\subsection{Step 3: Integrated Analysis}

In addition to the actual supply chain configuration, the simulation model adds new features in terms of inventory control policies, market demand pattern, and lead time.

\section{Experimental Design}

Starting from the inventory control policies used by retailers and DCs we propose a time-dependent safety stock as well as the optimization of the review period on the basis of the inventory cost of each item. Keeping fixed the customers' inter-arrival distribution, the demand intensity and variability have been modified to create alternative scenarios. The investigation and comparison of all possible scenarios requires a correct design of experiments. Note that there are four different factors: (1) inventory control policy; (2) lead time; (3) demand intensity; and (4) demand variability. Each factor has different levels: four different inventory control policies, three lead time values, three demand intensity levels, and three demand variability levels. Table 8 consists of a summary of factors and levels. Note that the IC1 is the actual inventory control policies at retailers, IC 3 at the distribution centers, the actual lead time is 3 days while medium demand variability and intensity depict the actual market situation.

Table 8: Factor matrix for a full factorial experimental design

\begin{tabular}{|l|c|c|c|c|}
\hline \multicolumn{1}{|c|}{ Level/Factors } & $\begin{array}{c}\text { X1 - Inventory } \\
\text { Control Policy }\end{array}$ & X2 - Lead Time & $\begin{array}{c}\text { X3 - Demand } \\
\text { Intensity }\end{array}$ & $\begin{array}{c}\text { X4 - Demand } \\
\text { Variability }\end{array}$ \\
\hline Level 1 - L1 & IC1 (L1) & 1 day & Low Intensity & Low Variability \\
\hline Level 2 - L2 & IC 2 (L2) & 3 days & Medium Intensity & $\begin{array}{c}\text { Medium } \\
\text { Variability }\end{array}$ \\
\hline Level 3 - L3 & IC3 (L3) & 5 days & High Intensity & High Variability \\
\hline Level 4 - L4 & IC4 (L4) & & & \\
\hline
\end{tabular}

A Full Factorial Experimental design based on factors levels combinations reported in table 8 creates a comprehensive set of different operative scenarios to be investigated

\section{Production runs and analysis}

As already mentioned, simulation results are expressed in terms of average fill rate. According to the supply chain experts' requests and based on authors'experience the following scenarios have been investigated:

1. the demand intensity scenario: pessimistic, actual and optimistic situation;

2. the demand variability scenario: pessimistic, actual and optimistic situation;

3. the lead time scenario: pessimistic, actual and optimistic situation.

Thanks to the simulation model we are able to investigate the behavior of the inventory control policy in each scenario. Figures 3 to figures 5 show the final simulation results for each scenario for one of the supply chain retailers (similar results are available for each supply chain node). 


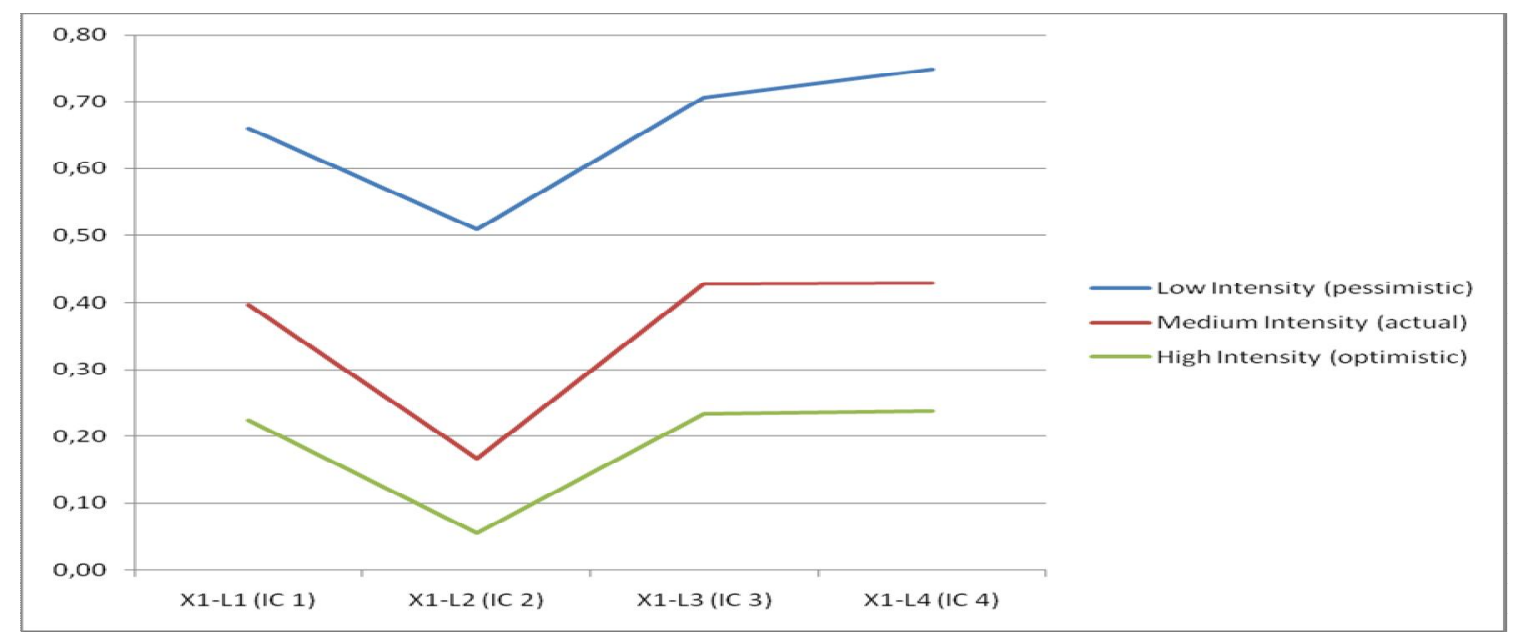

Figure 3. Fill rate versus different inventory control policies in the three demand intensity scenarios

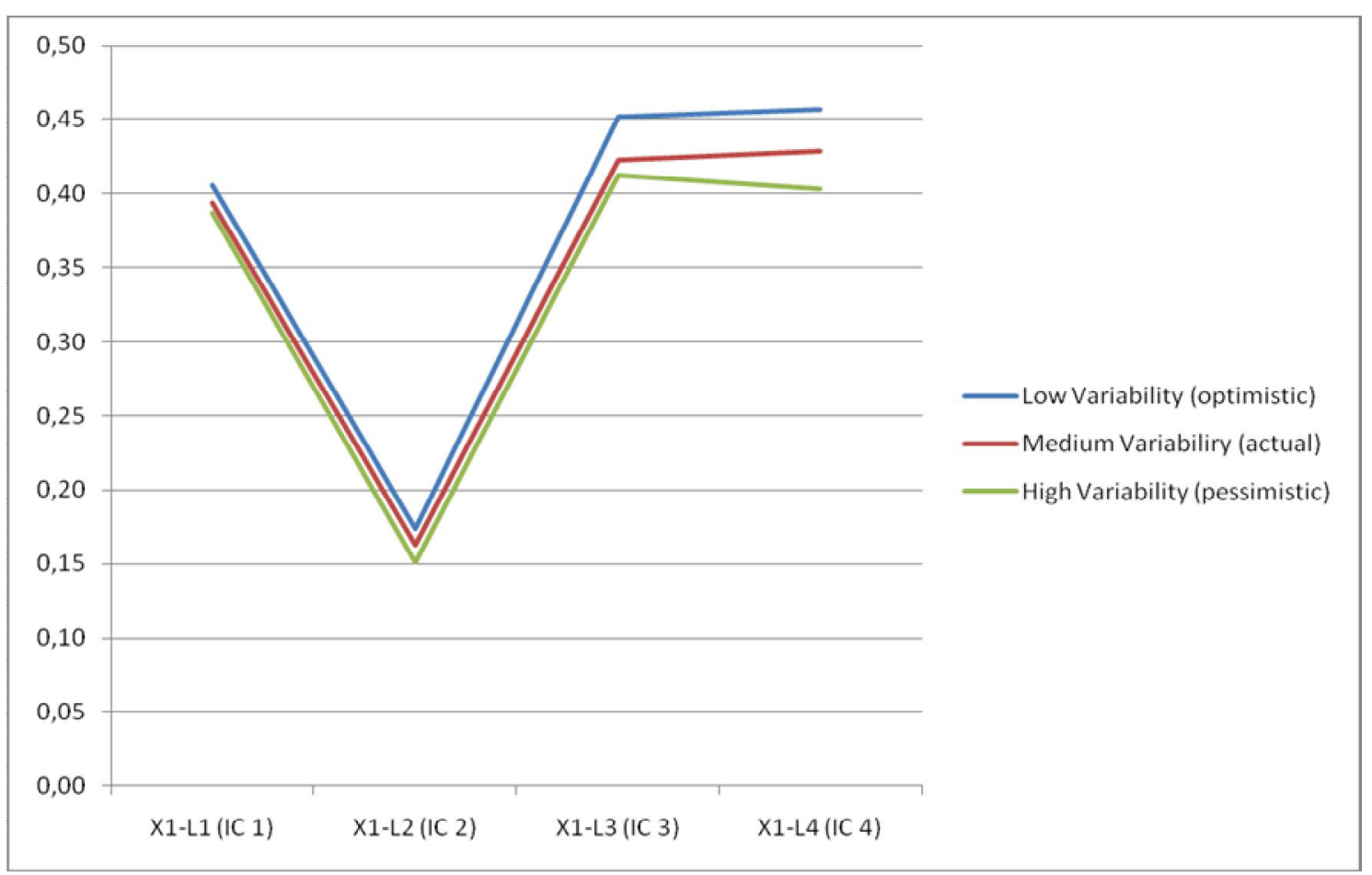

Figure 4. Fill rate versus different inventory control policies in the three demand variabilty scenarios 


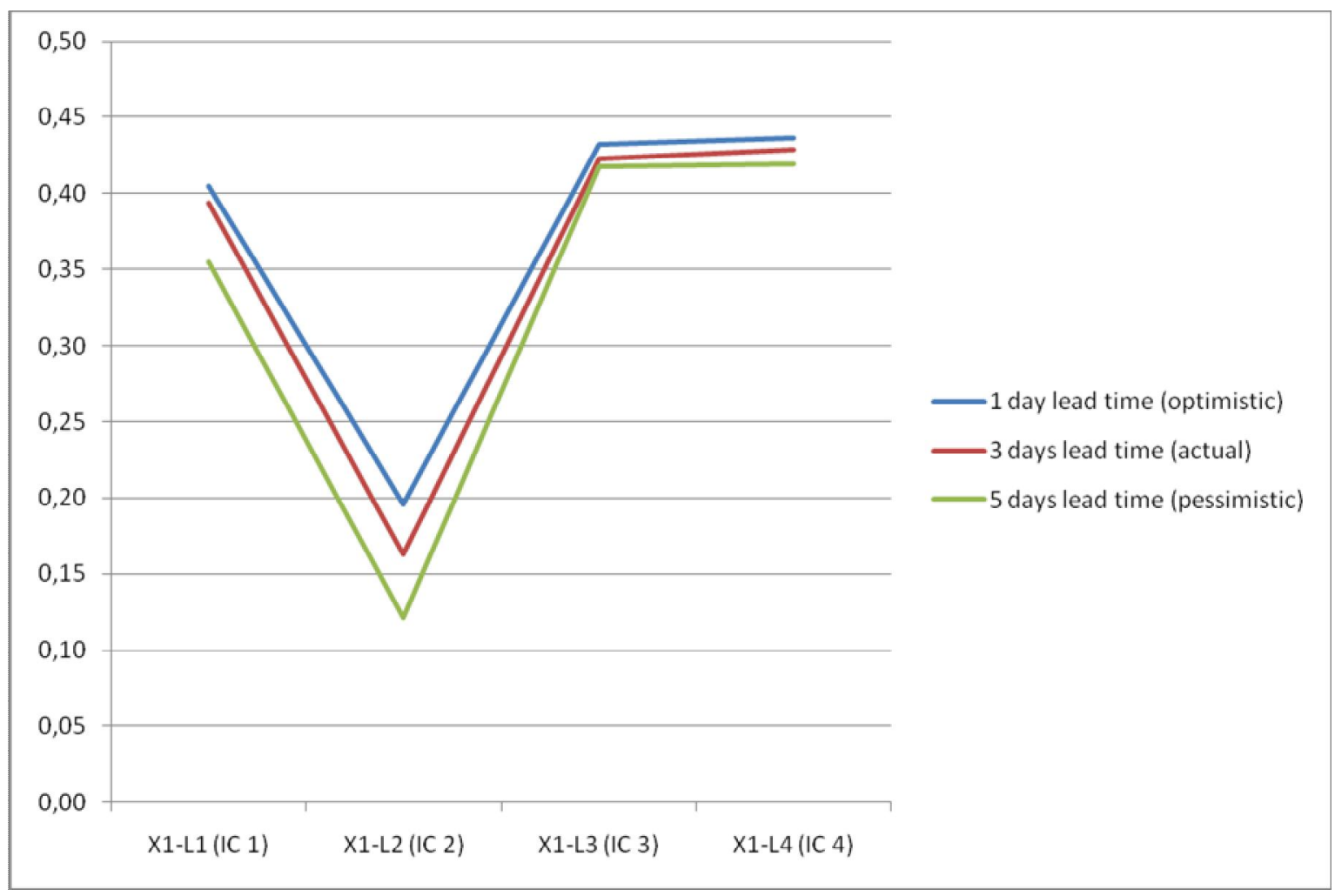

Figure 5. Fill rate versus different inventory control policies in the three lead times values scenarios

The analysis of each scenario allows an evaluation of the behavior of the inventory control policies and enables us to find the best performance of the inventory systems in terms of fill rate. The new scenarios are compared with the actual scenario in terms of what-if analysis. Similar results have been obtained for each supply chain node, for both retailers and distribution centers, analyzing and optimizing the inventory systems along the supply chain.

\section{Conclusions and Results}

Traditionally decisions made based on simulation models have been the outcomes of complicated statistical analyses and having confidence in them is a subjective matter. In this work we conducted a comprehensive investigation of the inventory systems along the supply chain under different demand patterns and lead times constraints applying an integrated approach based on Analytic Hierarchy Process a well know multi criteria technique and Simulation.

Integrated approaches usually offer improved methodologies to better model real-world complex systems and increase confidence in results analysis outcomes. In particular new methodological approach has the potentials to reduce the impact of statistics in building models in addition to other significant benefits.

The inventory management problem along the supply chain is usually characterized by multiple stochastic variables and critical factors. Factors such as lead times, demand intensity and variability may sometimes be so important that they override financial concerns. When incorporate multiple criteria we have a major reasonably simple set of inventory policies. The utilization of AHP provides a way to combine several multiple criteria. AHP generates a consistent measure that can be used for reclassification of inventory items in a simple simulation structure. A limitation of the approach is that more managerial time is needed to develop more information for each inventory item. However, the use of multiple criteria analysis can improve the quality and completeness of the inventory analysis. To make the results more manageable the use of AHP can be a powerful ally in supporting the policy development process. 
Finally we note that in today's manufacturing company, producers are paying increased attention to the need for product recovery activities. It is our aim to propose a further development of the present work applying an integrated multicriteria decision making model based on AHP and simulation for reverse logistics. In the AHP model we will evaluate a hierarchy of criteria and subcriteria, including costs and business relations, for critical decisions regarding the inventory problem in the case of reverse logistics.

\section{REFERENCES}

Balci, O., Verification, validation and testing. In Handbook of Simulation, edited by J. Banks, pp. 335-393, 1998 (Wiley Interscience: New York).

Bertsimas, D. and Thiele, A., A robust optimization approach to inventory theory. Oper. Res., 2006, 54, 150168.

Bruzzone, A.G., Viazzo, S., Massei, M. Computational Model for Retail Logistics, Proceedings of World Multiconference on Systemics, Cybernetics and Informatics, 2005, Orlando, Florida, USA.

Chan, T.S. and Chan, H.K., Simulation modelling for comparative evaluation of supply chain management strategies. Int. J. Adv. Manuf. Technol., 2005, 25, 998-1006.

Donald J. Bowersox, David J. Closs, M. Bixby Cooper. Supply Chain Logistics Management, 2002. McGrawHill Companies. Michigun State University.

D.H. Byun, The AHP approach for selecting an automobile purchase model, Information and Management 38 (5) (2001) 289-297.

F. De Felice, A.Petrillo, A multiple choice decision analysis: an integrated QFD - AHP model for the assessment of customer needs. International Journal of Engineering, Science and Technology Vol. 2, No. 9, 2010, pp. 25-38.

Jukka Korpela, Antti Lehmusvaarab, Jukka Nisonenc. Warehouse operator selection by combining AHP and DEA methodologies. International Journal Production Economics 108 (2007) 135-142.

Longo, F., Mirabelli, G. An Advanced Supply Chain Management Tool Based on Modeling \& Simulation, Computer and Industrial Engineering, 54(3), 2008, 570-588.

De Sensi, G., Longo, F., Mirabelli, G., 2008. Inventory policies analysis under demand patterns and lead times constraints in a real supply chain. International Journal of Production Research, 46, 6997-7016.

Longo F., Mirabelli, G. and Papoff, E., Modeling, analysis \& simulation of tubes manufacturing process and industrial operations controls, in Summer Computer Simulation Conference, Calgary, Canada, 2006, pp. 54-59.

Mithat Zeydan, Cüneyt Çolpan, Cemal Çobanoglu, A combined methodology for supplier selection and performance evaluation. Expert Systems with Applications 38 (2011) 2741-2751.

M.C.Y. Tam, V.M.R. Tummala, An Application of the AHP in vendor selection of a telecommunications system, Omega 29 (2) (2001) 171-182.

M.I. Al Khalil, Selecting the appropriate project delivery method using AHP, International Journal of Project Management 20 (2002) 469-474. 
Omkarprasad S. Vaidya, Sushil Kumar. Analytic hierarchy process: An overview of applications. European Journal of Operational Research 169 (2006) 1-29.

Ozan Cakir, Mustafa S. Canbolat. A web-based decision support system for multi-criteria inventory classification using fuzzy AHP methodology. Expert Systems with Applications 35 (2008) 1367-1378.

Prem Prakash Gajapal, L.S. Ganesh, Chandrasekharan Rajendran. Criticality analysi of spare parts using analytic hierarchy process. International Journal of Production Economics 35 (1994) 293-297.

Saaty, T.L., 2001. Decision making with independence and feedback: The Analytic Network Process, Pittsburgh, RWS Publications.

Saaty, T.L., 2005. Theory and Applications of the Analytic network Process: decision making with benefits, opportunities, costs, and risks. Pittsburg, PA: RWS Publications.

S.G. Li, X. Kuo The inventory management system for automobile spare parts in a central warehouse. Expert Systems with Applications 34 (2008) 1144-1153.

Wasner, M., Zapfel, G., 2004. An integrated multi-depot hublocation vehicle routing model for network planning of parcel service. International Journal of Production Economics 90 (3), 403-419.

Zhao, Q.H., Wang, S.Y., Lai, K.K., Xia, G.P., 2004. Model and algorithm of an inventory problem with the consideration of transportation cost. Computers \& Industrial Engineering 46 (2), 389-397.

Zipkin, P., Foundations of Inventory Management, 2000.McGraw-Hill Higher Education: Boston. 